\title{
Reciprocal Interferences of TNF- $\alpha$ and Wnt1/ $\beta$-Catenin Signaling Axes Shift Bone Marrow-Derived Stem Cells Towards Osteoblast Lineage after Ethanol Exposure
}

\author{
Yueping Chen ${ }^{\mathrm{a}, \mathrm{b}}$ Liang Chen ${ }^{\mathrm{b}}$ Qingshui Yin ${ }^{\mathrm{c}}$ Hui Gao $^{\mathrm{b}}$ Panfeng Dong ${ }^{\mathrm{b}}$ \\ Xiaoyun Zhang ${ }^{\mathrm{b}}$ Jie Kang ${ }^{\mathrm{b}}$
}

aSouthern Medical University, 2010 MD TongHe, Guangzhou, 'bepartment of Orthopedics, Affiliated Rui Kang Hospital of Guangxi Traditional Chinese Medical School, Nanning 530011, Guangxi Zhuang Autonomous Region, 'Orthopaedic Hospital, People's Liberation Army General Hospital of Guangzhou Military Command, Guangzhou 510010, Guangdong

\section{Key Words}

Ethanol - Multipotential mesenchymal stem cells (MSC) - Bone-marrow stem cells (BMSC) • Osteoblast • Osteogenesis • Adipogenisis $・$ TNF- $\alpha \cdot$ Wnt1 $\bullet \beta$-catenin $\bullet$ siRNA

\begin{abstract}
Background/Aims: We have reported in a separate study that alcohol exposure triggers activation of the TNF- $\alpha$ signaling pathway leading to an adverse shift of multipotential mesenchymal stem cells in bone marrow (BMSCs) away from osteogenesis towards adipogenesis. However, inhibition of TNF- $\alpha$ signaling only yielded moderate inhibition of adipogenesis. Here we showed that in addition to promoting the TNF- $\alpha$ signaling, alcohol also suppressed the Wnt1/ $\beta$-catenin signaling pathway. Methods: We treated primary BMSCs from human subjects with alcohol for 24 days. We measured changes of genes related to endoplasmic reticulum (ER) stress, adipogenic markers and osteogenic markers using quantitative real-time RT-PCR and Western blot analysis. We performed Alizarin red staining for osteogenesis. We also conducted assays for osteogenic biomarkers alkaline phosphatase, collagen-I and osteocalcin. Results: Wnt/ $\beta$-catenin signaling was markedly activated in BMSCs treated with osteogenic inducers relative to the control cells, as indicated by the increased levels of nuclear $\beta$-catenin along with reduced levels of cytosolic $\beta$-catenin, as well as increased protein levels of Wnt1. Activation of Wnt/ $\beta$-catenin signaling was significantly suppressed in BMSCs exposed to alcohol, which was reflected by downregulated expression of osteogenic marker genes Osf2/Cbfa1, osteopontin and osteocalcin, upregulated adipogenic marker PPARY2 and aP2, and reduced number of calcification nodules. In contrast, activation of Wnt/ $\beta$-catenin signaling by BIO favored osteogenesis even in the presence of alcohol. Simultaneous activation of Wnt1 by BIO and inhibition of TNF- $\alpha$ by 3,6'-dithiothalidomide


produced synergetic suppression of ethanol-induced adipogenic lineage compared to interference with either of them alone. Conclusion: This remarkable shift of BMSCs towards osteoblast lineage suggests the superiority of concordant and reciprocal interferences of the TNF- $\alpha$ and $\mathrm{Wnt} / \beta$-catenin pathways for promoting osteogenesis.

Copyright $(2013$ S. Karger AG, Basel

\section{Introduction}

Habitual consumption of excessive quantities of alcohol is commonly recognized as a major factor for osteopaenia and increased incidence of bone fracture in alcoholics [1-3]. The current consensus of both clinical and experimental studies is that alcohol-induced bone loss is mainly be due to the suppression of new bone formation with only relatively small changes (increase or decrease) occur in bone resorption [4]. In adults, the osteoblast, which is responsible for bone formation, is derived from multipotential mesenchymal stem cells in bone marrow (BMSC) [5-8]. The capacity and dynamics of these BMSCs to differentiate into osteoblasts plays a critical role in the cellular processes involved in the maintenance of the adult human skeleton.

The BMSCs have been proven to differentiate into multiple lineages and generate progenitors committed to one or more cell lines [9-11]. Among these multiple lineages, those of adipogenesis and osteogenesis are the most closely related: Several studies have provided substantial evidence that osteoblasts and adipocytes share a common progenitor: multipotential BMSCs [5-8, 12-14]. An inverse relationship has been demonstrated between osteogenesis and adipogenesis suggesting the possible reciprocal relationship between the two differentiation pathways [15-17]. There has been evidence for the differentiation switching between these two cell lineages, suggesting a large degree of plasticity between osteoblasts and adipocytes $[18,19]$. Because the relationship between adipogenesis and osteogenesis is reciprocal and the adipocytic and osteogenic cells share a common lineage, it is possible that inhibition of adipogenesis may provide an approach to prevent or treat osteoporosis or other bone diseases. Thus, the signal transduction pathways implicated in these processes are evaluated as potential targets for therapeutic intervention of osteopenic disorders.

Wnt1 was originally described as a proto-oncogene in mouse mammary tumor induced by mouse mammary tumor virus [20]. Genetic evidence indicates that Wnt signaling is critically involved in bone homeostasis and is essential for normal osteogenesis [21-25]. Enhancement of Wht signaling either by Wnt overexpression [26] or deficiency of Wnt antagonists [27] is associated with increased bone formation in mice and humans. A recent study by Chen etal. [28] has elucidated the critical role of Wnt/ $\beta$-catenin signaling in mediating the ethanol-induced adipogenic lineage commitment of mesenchymal stem cells: ethanol inhibits bone formation through stimulation of oxidative stress to suppress Wnt signaling.

Several studies [29-33] have provided evidence that alcohol shifts lineage commitment and differentiation of BMSCs from osteogenesis to adipogenesis by upregulation of gene expression for peroxisome proliferator-activated receptor gamma (PPAR $\gamma$ ); however, the molecular mechanism underlying the reciprocal relationship is not yet well understood. We have found in a separate study that alcohol exposure triggers ER stress in BMSCs where ATF4 and CHOP are excessively upregulated and activated. These changes result in activation of the TNF- $\alpha$ signaling pathway leading to an unwanted shift of BMSCs away from osteogenesis towards adipogenesis. Here we confirmed the results reported by Chen et al. [28] that alcohol-induced ER stress suppresses the Wnt1/ $\beta$-catenin signaling pathway favoring adipogenic remodeling of BMSCs. We therefore proposed the following ethanolinduced signaling pathway leading to inhibition of osteogenesis: Ethanol $\rightarrow$ ER stress $\uparrow \rightarrow$ ATF4 and CHOP $\uparrow /$ TNF- $\alpha \uparrow \uparrow /$ Wnt1/ $\beta$-catenin $\downarrow \downarrow \rightarrow$ Osteoblasts $\downarrow \downarrow \downarrow$. These data explain why ATF4 and CHOP which are normally required for osteogenic shift of lineage enter into adipogenic remodeling when overexpressed during ER stress. Obviously, targeting ATF4 and CHOP may not be an ideal strategy for promoting osteogenesis as while silencing ATF4 
and CHOP may alleviate ER stress this maneuver may well damage the osteogenic potential of BMSCs. Moreover, targeting either TNF- $\alpha$ or Wnt signaling may not yield optimal effects in preserving osteogenic lineage of BMSCs. We therefore examined the potential benefit to osteogenesis via targeting the downstream components of the signaling pathway shown above by simultaneous silencing TNF- $\alpha$ and activating Wnt1.

\section{Materials and Methods}

\section{Human BMSCs preparation and culture}

Bone marrow samples for isolating BMSCs were collected from cancellous bony fragments of patients (age range 35-50 years; $n=6$ ) undergoing routine total hip replacement surgery in the Orthopaedic Hospital, the People's Liberation Army General Hospital of Guangzhou Military Command. Written informed consent was obtained from all patients. The study protocol was approved by the Ethics Committee of the People's Liberation Army General Hospital of Guangzhou Military Command. None of the patients were alcoholics, showed any evidence of concurrent illness, and received any medications that could affect bone metabolism.

The procedures for preparing primary BMSCs from human subjects were essentially the same as described by Huang et al [18], which was a modified method of Percoll density gradient centrifugation [34]. Briefly, when BMSC cultures became nearly confluent, cells were trypsinized and plated in $75 \mathrm{~cm}^{2}$ flasks or 6-well plates for protein analysis or RNA analysis and cytochemical analysis, respectively. Only cells at passage two or three were used. Cell surface markers were evaluated by flow cytometry (Cytomics FC-500, Beckman Coulter, CA, USA) using the monoclonal antibodies conjugated with fluorescein isothiocyanate (FITC) or phycoerythrine (PE): CD34-FITC, CD105-PE, CD166-PE.

\section{Alcohol treatment and adipogenic induction}

BMSCs at passage two or three were divided into three groups: control group, osteogenic group, and alcohol group. The control group was cultured in Dulbecco's modified Eagle's medium (DMEM) with 10\% FBS, the osteogenic group in DMEM containing osteogenic inducers $(10 \mathrm{mM} \beta$-glycerophosphate, $50 \mu \mathrm{g} /$ $\mathrm{ml}$ ascorbic acid, and $0.1 \mu \mathrm{M}$ dexamethasone) supplemented with 10\% FBS [18], and the alcohol group in DMEM containing 10\% FBS, $100 \mathrm{mM}$ alcohol, and osteogenic inducers. All cultures were maintained for 24 days prior to experimental measurements and treatments were implemented as to be specified. This concentration of alcohol is approximately twice as much as its $\mathrm{IC}_{50}$ for inhibiting osteoblast proliferation in vitro and also represents a level within the physiological range observed in actively imbibing alcoholics $[18,35]$. To supplement the potential loss of alcohol because of its volatile nature and maintain the constant alcohol concentration, we followed the procedures described by Huang et al. [18] by placing a reservoir containing the same concentration of alcohol in a chamber during culture, which was replenished daily.

\section{Drug treatment}

Approximately $4 \times 10^{5}$ cells were treated in a plastic dish with a selective inhibitor of TNF- $\alpha$ biosynthesis 3,6'-dithiothalidomide (10 $\mu \mathrm{M} ; \mathrm{C}_{32} \mathrm{H}_{32} \mathrm{~F}_{3} \mathrm{~N}_{3} \mathrm{O}_{2}$; Santa Cruz Biotechnology) [3, 4]. XAV939 (2-(4-(trifluoromethyl)phenyl)-7,8-dihydro-5H-thiopyrano[4,3-d]pyrimidin-4-ol) is a cell permeable, small molecule inhibitor of the Wnt $/ \beta$-catenin pathway $[1,2]$. It inhibits tankyrase $1\left(\mathrm{IC}_{50}=11 \mathrm{nM}\right)$ and tankyrase $2\left(\mathrm{IC}_{50}=4 \mathrm{nM}\right)$, stabilizes axin and stimulates $\beta$-catenin degradation. XAV-939 was solubilized in DMSO at $55^{\circ} \mathrm{C}$ to make a $10 \mathrm{mM}$ stock solution which may be diluted later to a working concentration of $100 \mu \mathrm{M}$.

To activate Wnt/ $\beta$-catenin signaling pathway, BMSCs were treated with $20 \mu \mathrm{M}$ BIO (Sigma) for $24 \mathrm{~h}$ $[36,37]$.

\section{Alizarin red staining}

To detect mineral deposition, alizarin red staining was performed on BMSCs after cultured in chamber slides for 28 days. Cells were fixed in $4 \%$ formaldehyde in PBS at $4{ }^{\circ} \mathrm{C}$ for $45 \mathrm{~min}$. Next, the cells were washed and exposed to alizarin red ( $2 \%$ aqueous, Sigma) for $10 \mathrm{~min}$ at RT, and washed again with distilled water. Finally, cells were examined under a phase contrast microscope. 


\section{Real-time PCR}

Total RNA was prepared from cultures on day ten, using the Trizol reagent (Invitrogen) according to the manufacturer's instructions. Quantitative real-time RT-PCR analysis was performed with the SYBR Green RT-PCR Kit (Qiagen, Valencia, CA) using the GeneAmp 5700 sequence detection system (Applied Biosystems) according to the manufacturer's instructions. Levels of mRNAs of osteogenic makers Osf2/ Cbfa1 [38], osteopontin [39] and osteocalcin [40], adipogenic markers (PPAR 2 and aP2) [41], and Wnt1 were determined. Samples were assayed in triplicates, and the values were normalized to the relative amounts of $\beta$-actin, and the results were interpreted using the $\Delta \mathrm{CT}$ method.

\section{Immunoblots}

Cells were lysed in a RIPA lysis buffer containing inhibitors for proteases and phosphatases. Protein concentration was determined by the protein content was determined by BCA Protein Assay Kit using bovine serum albumin as the standard (Pierce, USA). Equal amounts of protein samples $(\sim 25 \mu \mathrm{g})$ were fractionated by SDS-PAGE (12\% polyacrylamide gels) and electrophoretically transferred to PVDF membrane (Millipore, Bedford, MA) using a Mini Trans-blot (Bio-Rad Laboratories, Shanghai). The membranes were blocked for $1 \mathrm{~h}$ in defatted milk (10\% in Tris-buffered saline with Tween-20 buffer), and incubated with primary antibodies $(1: 1000)$ at $4^{\circ} \mathrm{C}$ overnight. The primary antibodies included rabbit polyclonal anti-PPAR $\gamma 2$, anti-Osf2/Cbfa1, and anti-Wnt1, all purchased from Santa Cruz Biotech (CA, USA). Next day, the membrane was incubated with horseradish peroxidase-conjugated secondary antibody (1:1,000; Molecular Probes) diluted in PBS for $2 \mathrm{~h}$ at RT. Finally, the membrane was rinsed with PBS before scanning using the Infrared Imaging System (LI-COR Biosciences). $\beta$-actin was used as an internal control for equal input of protein samples, using anti- $\beta$-actin antibody. Western blot bands were quantified using the LI-COR ${ }^{\circledR}$-Image Studio Lite software by measuring the band intensity (Area $\times$ OD) for each group and normalizing to $\beta$-actin. The final results are expressed as fold changes by normalizing the data to the control values.

Assays for osteogenic biomarkers alkaline phosphatase, collagen-I and osteocalcin

Alkaline phosphatase activity was determined by measuring the formation of p-nitrophenol from p-nitrophenyl phosphate with the ALP Optimised clorimetric test kit according to the manufacturer's instructions. C-terminal propeptide of type I collagen was measured by enzyme-linked immunoadsorbent assay with a MetraCICPEIAkit(Quidel,SanDiego,CA). Forassessing osteocalcin, 1,25-dihydroxycholecalciferol $(0.1 \mu \mathrm{M})$ was added into the culture and incubated for $24 \mathrm{~h}$. A Metra Osteocalcin EIA kit (Quidel) was used for osteocalcin production measurement in the culture media on day ten. The values of alkaline phosphatase activity, type I procollagen and osteocalcin production were normalized to total protein determined with Bio-Rad total protein assay reagents (Bio-Rad, Hercules, CA).

Data analysis

Results are presented as mean \pm S.E.M. Multiple comparisons were performed using one-way ANOVA and Bonferroni after test comparison (Prism software; GraphPad, San Diego, CA). A $P$ value $<0.05$ was considered significant.

\section{Results}

Characterization of BMSCS

Expression of CD34, CD105, and CD166 in the BMSCs were determined by flow cytometry using the monoclonal antibodies CD34-FITC, CD105-PE, and CD166-PE in the undifferentiated states. The BMSCs consistently expressed BMSC markers CD105 and CD166, but did not express hematopoietic cell marker CD34. The cells prepared by Percoll separation were composed of $98.6 \% \pm 5.5 \%$ of CD34 negative cells, $94.9 \% \pm 7.2 \%$ of CD105 positive cells and $93.7 \% \pm 6.3 \%$ of CD166 positive cells. These results indicated the purity of BMSCs in our cell preparation.

Alcohol-induced dissipation of osteogenic lineage in BMSCS

We first compared the osteogenic and adipogenic status among the three groups by assessing the relative expression of osteogenic marker genes Osf2/Cbfa1 and osteocalcin, 
Fig. 1. Evidence for alcohol-induced dissipation of osteogenic lineage in bone marrow-derived stem cells (BMSCs). A, Upregulation of osteogenic marker Osf2/Cbfa1 mRNA and downregulation of PPAR 2 and aP2 mRNAs in BMSCs treated with osteogenic inducers (the Osteogenic group), compared to untreated control cells (the Control group). B, Alcohol exposure (100 mM for 24 days) reversed all above changes. C, Upregulation of osteogenic marker Osf2/Cbfa1 protein and downregulation of PPAR $\gamma 2$ and aP2 proteins in BMSCs treated with osteogenic inducers (the Osteogenic group), reversal of these changes by alcohol (the Alcohol group). C: the Control group; O: the Osteogenic group; A: the Alcohol group in the presence of osteogenic inducers. ${ }^{*} P<0.01$ Alcohol vs Control; ${ }^{* *} P<0.01$ Osteogenesis vs Control; ${ }^{* * *} P<0.001$ Osteogenesis vs Control; ${ }^{++} P<0.001$ Alcohol vs Osteogenesis; $\mathrm{n}=5$.

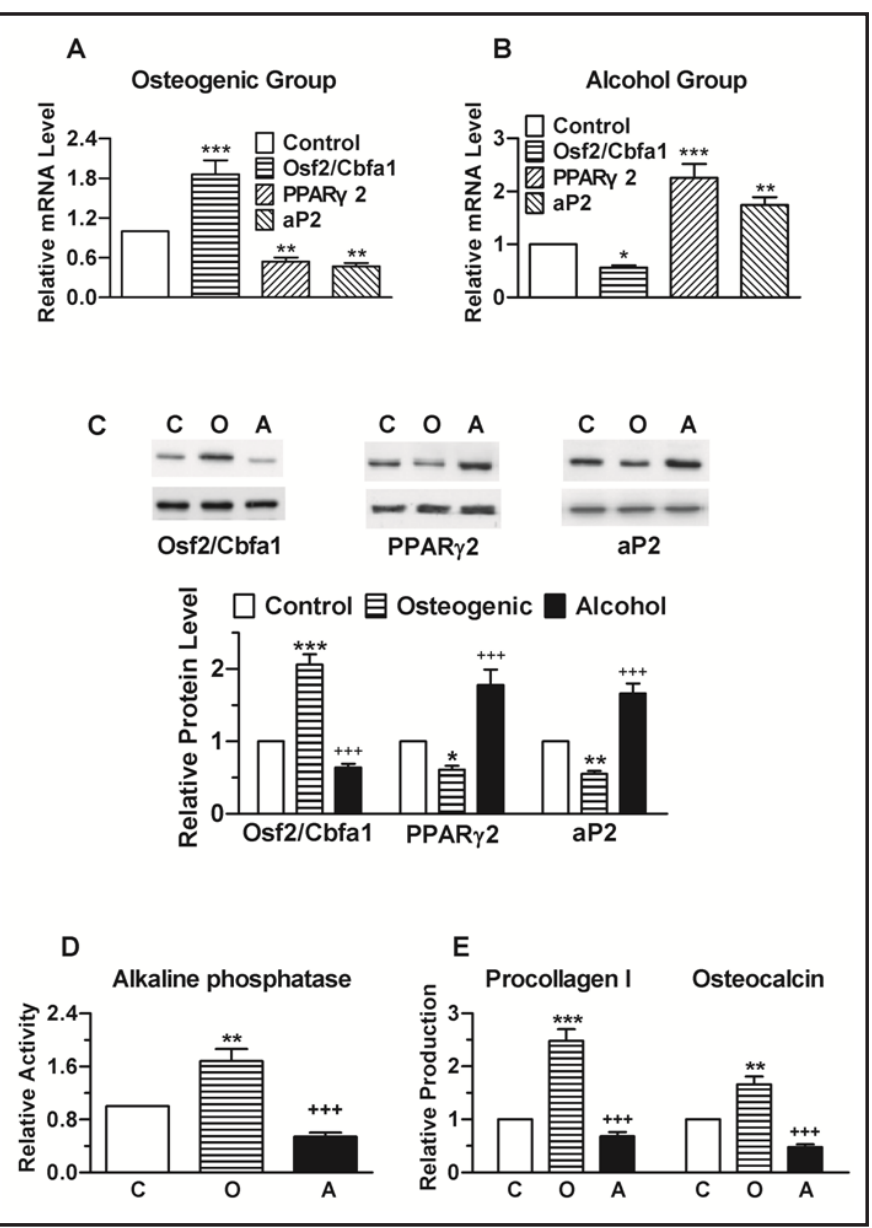

Fig. 2. Evidence for the alcohol-induced decrease in osteogenesis in BMSCs. Upper panels: typical images of Alizarin red staining for quantification of calcification nodules. Lower pane: mean data of the number of calcification nodules. ${ }^{* * *} P<0.001$ Osteogenesis vs Control; ${ }^{++} P<0.01$ Alcohol vs Osteogenesis; $\mathrm{n}=4$.

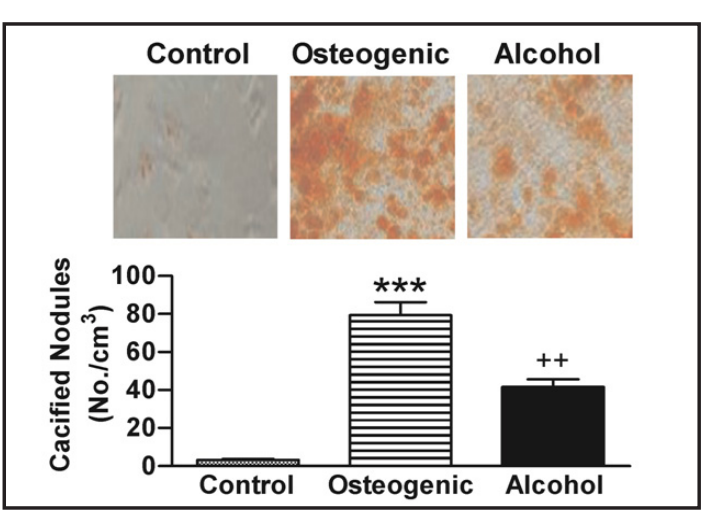

and adipogenic marker PPAR $\gamma 2$ and aP2 at both mRNA and protein levels, in BMSCs.

Quantitative analysis of the mRNA levels by real-time RT-PCR (qPCR) revealed that Osf2/Cbfa1 and osteocalcin mRNAs in the osteogenic group were significantly upregulated $(P<0.001)$, whereas PPAR $\gamma 2$ and aP2 mRNAs were downregulated $(P<0.05)$, compared to the control group (Fig. 1A). These changes were all inverted by alcohol: in the alcohol group, expression of Osf $2 / \mathrm{Cbfa} 1$ and osteocalcin was markedly downregulated $(P<0.01)$, along with robust increases in the levels of PPAR $\gamma 2$ and aP2 mRNAs $(P<0.001)$, relative to the osteogenic group (Fig. 1B).

Similar results were obtained from Western blot analysis. Alcohol reversed the elevated protein levels of Osf2/Cbfa1 and the diminished levels of PPAR $\gamma 2$ and aP2 observed in the osteogenic group (Fig. 1C). Additionally, alkaline phosphatase activity was enhanced, and 


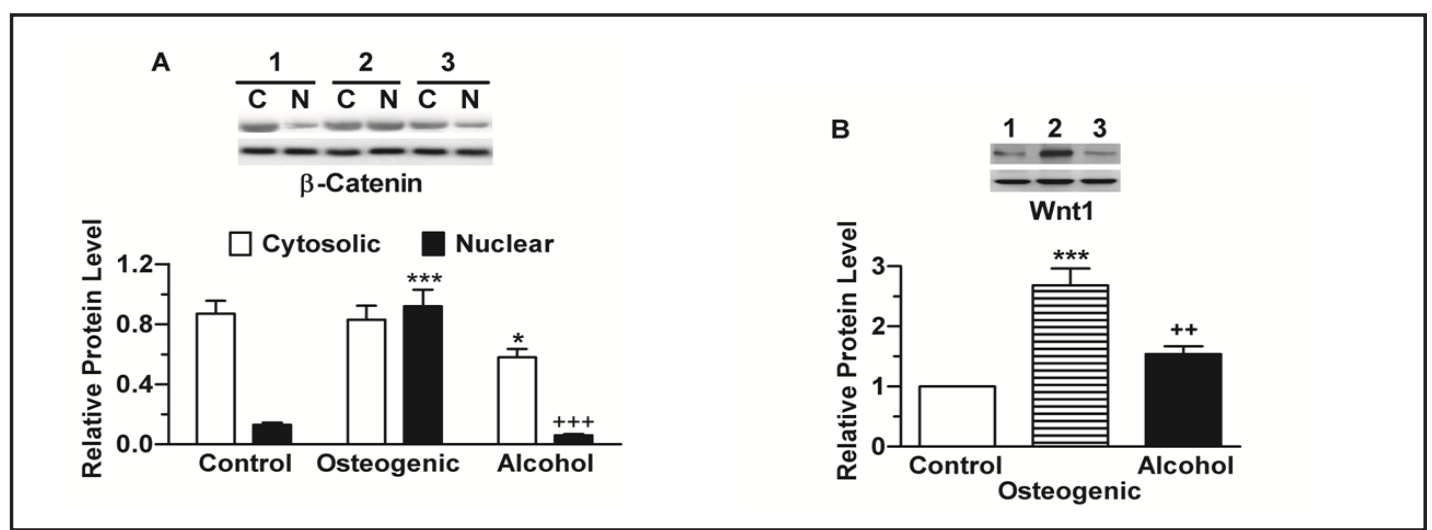

Fig. 3. Evidence for the role of Wnt/ $\beta$-catenin signaling in osteogenesis and alcohol-induced adipogenic lineage shift of BMSCs. A, Enhanced nuclear translocation of $\beta$-catenin, as indicated by the relative increase of $\beta$-catenin in the nucleus and decrease in the cytoplasm in cells treated by osteogenic inducers, and the reversal of these changes by alcohol exposure (100 mM for 24 days). B, Upregulation of Wnt1 protein in the Osteogenic group and downregulation in the Alcohol group. 1: the Control group; 2: the Osteogenic group; 3: the Alcohol group in the presence of osteogenic inducers; C: cytoplasm; N: nucleus. ${ }^{* * *} P<0.001$ Osteogenesis vs Control; ${ }^{++} P<0.01$ Alcohol vs Osteogenesis; ${ }^{++} P<0.001$ Alcohol vs Osteogenesis; $\mathrm{n}=4$.

Fig. 4. Inhibition of $\mathrm{Wnt} / \beta$-catenin signaling by XAV939 $(100 \mu \mathrm{M})$ suppresses osteogenesis of BMSCs. A, XAV939 decreased the osteogenic marker Osf2/ Cbfa1 protein level, alkaline phosphatase activity, and procollagen I and osteocalcin productions. B, XAV939 increased the adipogenic markers PPAR $\gamma 2$ and aP2 protein levels. C, XAV939 reduced the number of calcified nodules. O: the Osteogenic group as control; X: the Osteogenic group treated with XAV939. ${ }^{* *} P<0.01$ XAV939 vs Control; ${ }^{* * *} P<0.001$ XAV939 vs Osteogenesis; $\mathrm{n}=5$.

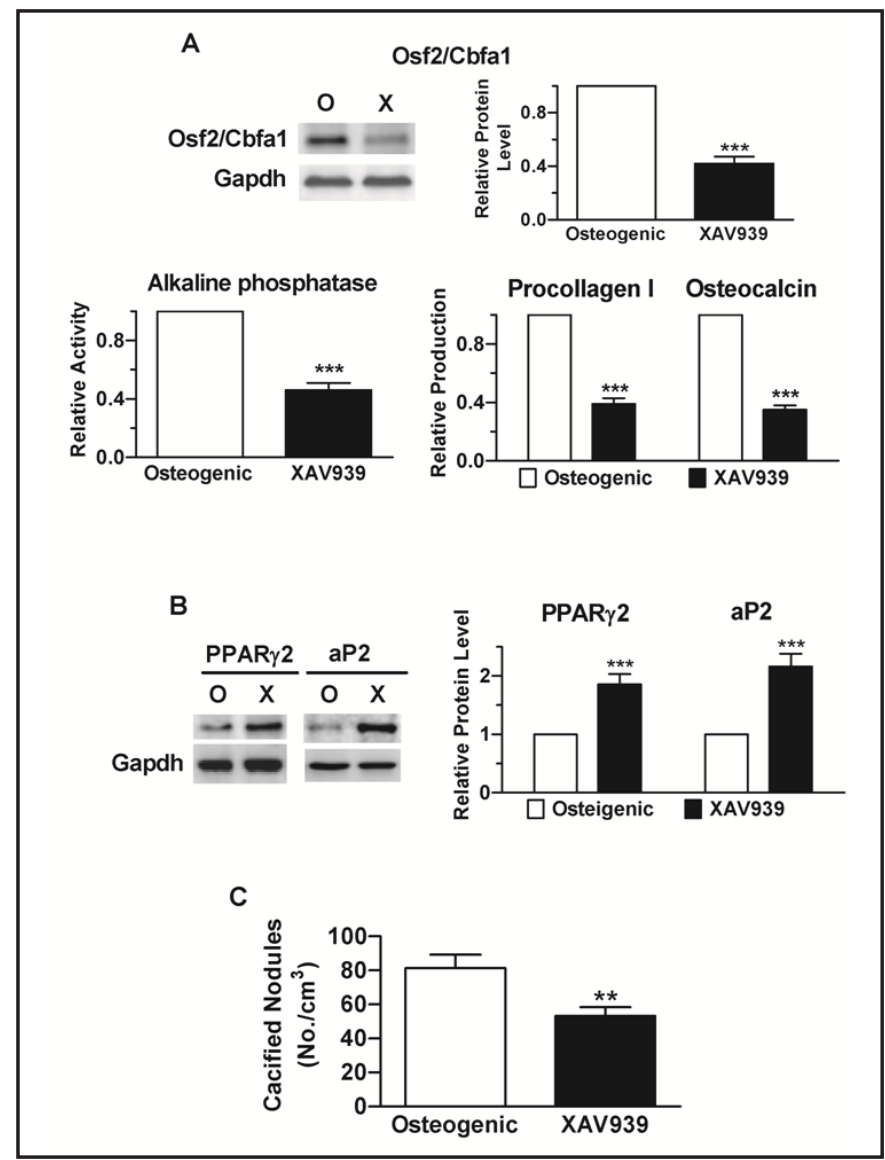

type I collagen (procollagen I) and osteocalcin productions were increased by osteogenic inducers, which were all abolished by alcohol exposure (Fig. 1D).

Moreover, Alizarin red staining showed that throughout the 28-day culture period, the number of calcification nodules in the osteogenic group was $79.3 \pm 6.5 / \mathrm{cm}^{2}$, which was significantly decreased by nearly $50 \%$ by alcohol $(P<0.001$; Fig. 2$)$. 
Fig. 5. Activation of $\mathrm{Wnt} / \beta$-catenin signaling by BIO $(20 \mu \mathrm{M})$ suppresses alcohol-induced adipogenesis of BMSCs. A, BIO increased the osteogenic marker Osf2/Cbfa1 protein level, alkaline phosphatase activity, and procollagen I and osteocalcin productions. B, BIO decreased the adipogenic markers PPAR 2 and aP2 protein levels. C, BIO increased the number of calcified nodules. A: the Alcohol group as control; B: the Alcohol group treated with BIO. ${ }^{*} P<0.05$; ${ }^{* *} P<0.01$; ${ }^{* * *} P<0.001$ BIO vs Alcohol; $\mathrm{n}=4$.

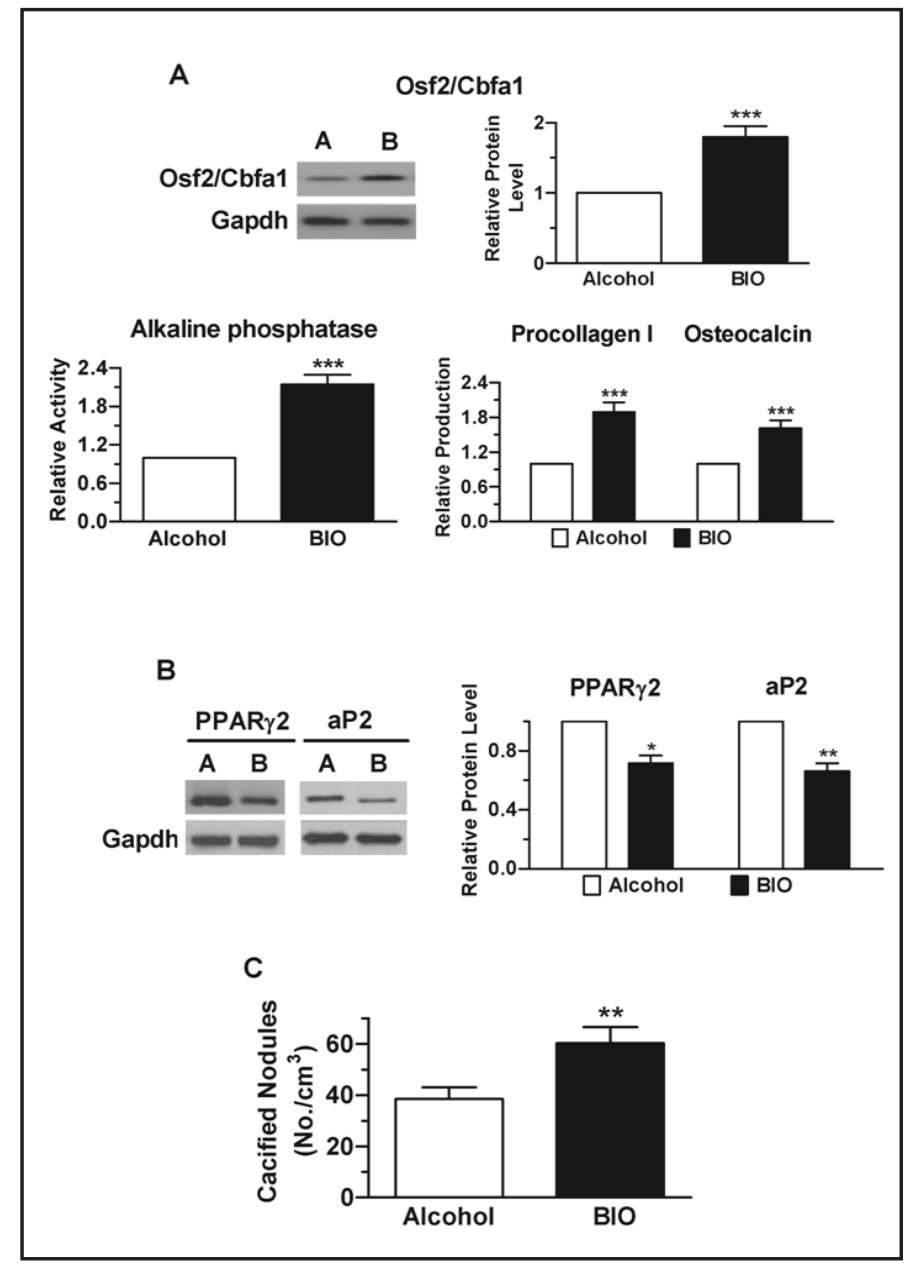

Inhibition of Wnt1/3-catenin and alcohol-induced dissipation of osteogenic lineage

Wnt1 has been shown to play a crucial role in bone homeostasis and normal osteogenesis [21-28]. To investigate if Wnt1 is involved in alcohol-induced dissipation of osteogenic lineage of BMSCs, we evaluated the effects of Wnt/ $\beta$-catenin inhibition and activation. As illustrated in Fig. 3, Wnt/ $\beta$-catenin signaling was markedly activated in the osteogenic group relative to the control cells, as indicated by the increased levels of nuclear $\beta$-catenin along with reduced levels of cytosolic $\beta$-catenin (Fig. 3A), as well as increased protein levels of Wnt1 (Fig. 3B). Activation of Wnt/ $\beta$-catenin signaling was significantly suppressed in BMSCs exposed to alcohol. It was noted that not only was the nuclear translocation of $\beta$-catenin enhanced but also was its expression level elevated, as indicated by the increased sum of cytosolic and nuclear $\beta$-catenin protein.

Moreover, in the osteogenic group treated with a Wnt/ $\beta$-catenin signaling inhibitor XAV939, the osteogenic marker genes were downregulated (Fig. 4A), whereas the adipogenic markers were upregulated (Fig. 4B). The number of calcification nodules in the osteogenic group was also decreased by $30 \%$ by XAV939 ( $P<0.001$; Fig. 4 C).

On the contrary, activation of Wnt/ $\beta$-catenin signaling by BIO in alcohol-treated BMSCs caused the opposite changes: upregulation of the osteogenic markers (Fig. 5A), downregulation of adipogenic markers (Fig. 5B), and increase in the number of calcification nodules (Fig. 5C). Osf2/Cbfa1 by $\sim 1.8$ fold, alkaline phosphatase activity by $\sim 2.1$ fold, procollagen I by $\sim 1.9$ fold, and osteocalcin production by $\sim 1.6$ fold (Fig. 5A). PPAR $\gamma 2$ and aP2 were decreased by $\sim 28 \%$ and $\sim 33 \%$, respectively, by BIO (Fig. $5 B$ ). The number of calcification nodules was increased by $\sim 1.5 \%$ (Fig. $5 \mathrm{C}$ ). 
Fig. 6. Simultaneous activation of $\mathrm{Wnt} / \beta$ catenin signaling by BIO $(20 \mu \mathrm{M})$ and inhibition of TNF- $\alpha$ signaling by 3,6'-dithiothalidomide (DT; $10 \mu \mathrm{M}$ ) yield superior suppressive effects on alcohol-induced adipogenesis lineage shift of BMSCs. A, BIO+DT increased the osteogenic marker Osf2/ Cbfa1 protein level, alkaline phosphatase activity, and procollagen I and osteocalcin productions. B, BIO+DT decreased the adipogenic markers PPAR $\gamma 2$ and $\mathrm{aP} 2$ protein levels. $\mathrm{C}, \mathrm{BIO}+\mathrm{DT}$ increased the number of calcified nodules. A: the Alcohol group as control; B: the Alcohol group treated with BIO+DT. ${ }^{* *} P<0.01 ;{ }^{* *} P<0.001 \mathrm{BIO}+\mathrm{DT} v s$ Alcohol; $\mathrm{n}=4$.

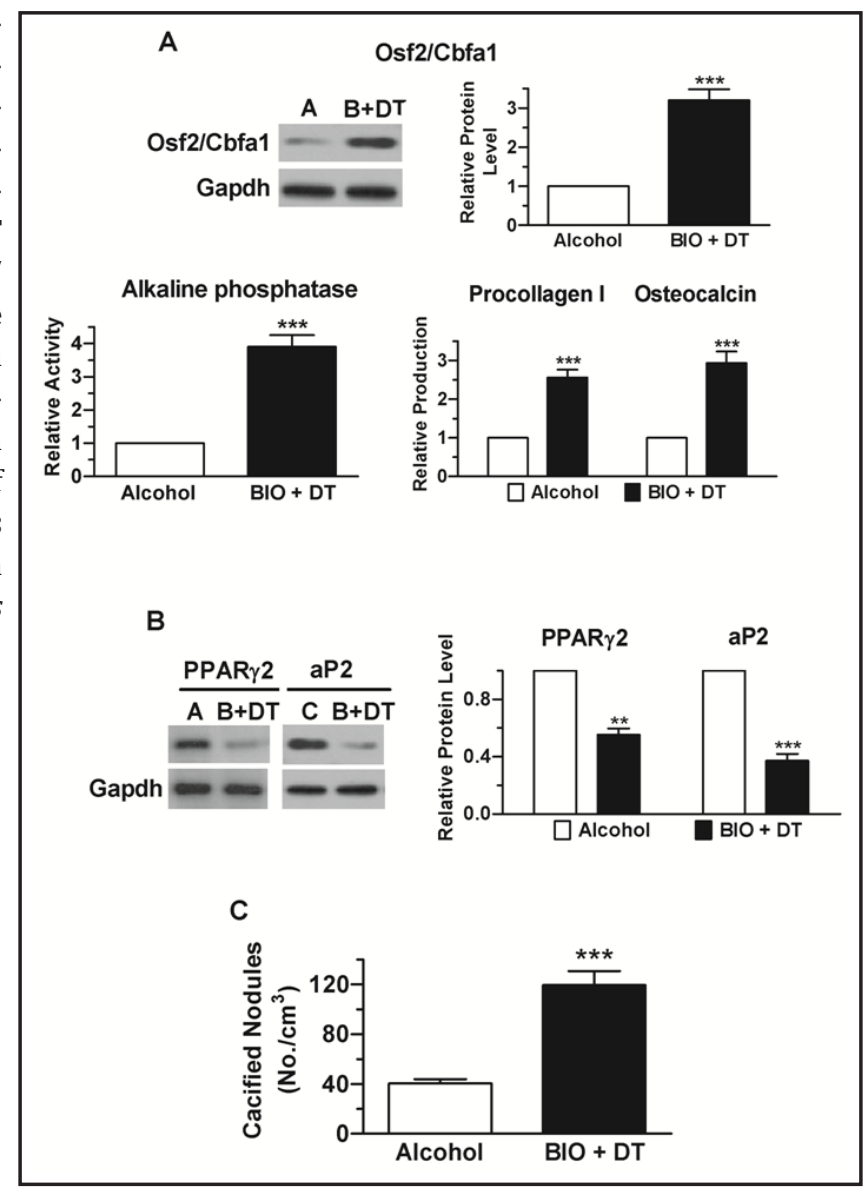

Osteogenic lineage shift of BMSCs induced by simultaneous knockdown of TNF- $\alpha$ and upregulation of Wnt1

It was noted that the efficacy of promoting osteogenesis or suppressing adipogenesis by BIO $(20 \mu \mathrm{M})$ was moderate and suboptimal based on the data shown in Figure 5. Increasing $\mathrm{BIO}$ concentration to achieve a greater extent of Wnt/ $\beta$-catenin signaling activation might improve the efficacy; however, this maneuver could cause changes of other signaling pathways that could obscure and confound the interpretation of data. It is therefore more desirable to take alternative approaches. As already mentioned, we have shown in our separate study that alcohol exposure upregulated TNF- $\alpha$ signaling favoring adipogenic lineage of BMSCs. These findings prompted us to test if simultaneous inhibition of TNF- $\alpha$ signaling and activation of Wnt/ $\beta$-catenin signaling could yield more powerful suppressing effects on alcohol-induced dissipation of osteogenic lineage. The results presented in Fig. 6 provide supportive evidence for the notion. Concordant treatment of BMSCs with 3,6'-dithiothalidomide $(10 \mu \mathrm{M})$ and BIO $(20 \mu \mathrm{M})$ in the alcohol group generated superior promotion of osteoblast lineage shift, or inhibition of adipocytes lineage, after ethanol exposure. Osf2/Cbfa1 was upregulated by 3.2 fold, alkaline phosphatase activity enhanced by $\sim 3.9$ fold, and procollagen I and osteocalcin productions by $\sim 2.6$ fold and $\sim 2.9$ fold, respectively (Fig. 6A). PPAR $\gamma 2$ and aP2 were decreased by $\sim 45 \%$ and $\sim 63 \%$, respectively, by BIO (Fig. $6 \mathrm{~B}$ ). The number of calcification nodules was increased by $\sim 2.9 \%$ (Fig. 6C).

\section{Discussion}

Both TNF- $\alpha$ and Wnt1 have been shown to play a crucial role in bone formation and homeostasis with Wnt1 being essential for normal osteogenesis and TNF- $\alpha$ being anti- 
osteogenic. The main goal of this study was to examine our hypothesis that concordant reciprocal interventions of TNF- $\alpha$ and Wnt1 signaling produce more thorough inhibition of ethanol-induced adipogenesis in human BMSCs. The main findings of the present study are (1) Wnt/ $\beta$-catenin signaling in BMSCs was significantly suppressed by ethanol, indicating its involvement in the impaired osteogenesis; and (2) simultaneous activation of Wht/ $\beta$-catenin signaling and inhibition of TNF- $\alpha$ signaling produced synergetic suppression of ethanolinduced adipogenic lineage compared to intervention of either of them alone.

Wnt signaling has been known to participate in osteogenesis and bone homeostasis [2128] and stimulation of Wnt signaling either by Wnt overexpression [27] or deficiency of Wnt antagonists [28] is implicated in increased bone formation in mice and humans. Chen et al. [28] provide the first evidence for the role of Wnt/ $\beta$-catenin signaling in the regulation of osteogenic and adipogenic lineages of mesenchymal stromal cells with prolonged exposure to alcohol. Our results are consistentwith this study demonstrating theimportance ofWnt/ $\beta$-catenin signaling against alcohol-induced adipogenic lineage commitment. Moreover, we showed that Wnt/ -catenin signaling was substantially activated in BMSCs treated with osteogenic inducers relative to untreated control cells, as indicated by the enhanced nuclear translocation of $\beta$-catenin, as well as increased protein levels of Wnt1. Artificial inhibition of Wnt/ $\beta$-catenin signaling inhibited osteogenesis even in the presence of osteogenic inducers. On the other hand, Wnt/ $\beta$-catenin signaling was significantly suppressed in BMSCs exposed to alcohol. Artificial activation of Wnt/ $\beta$-catenin signaling in cells treated with alcohol alleviated the adipogenesis. This study did not get into the mechanisms for the activation of Wnt/ -catenin signaling during osteogenesis and inhibition during adipogenesis induced by alcohol. It is possible that it is ER stress induced by alcohol that inhibited Wnt/ $\beta$-catenin signaling, as it has been shown that ER stress suppresses Wnt/ $\beta$-catenin signaling $[41,42]$ and in our separate study, we have addressed the critical role of ER stress in adipogenic lineage shift of BMSCs after exposure to ethanol. Furthermore, it has been shown that oxidative stress downregulates $\mathrm{Wnt} / \beta$-catenin signaling, and the antioxidant $\mathrm{N}$-acetylcysteine is able to reverse this downregulation and block bone loss [28].

It is noted thateither activation ofWnt/ $\beta$-catenin signaling alone or inhibition of TNF- $\alpha$ signalingaloneallowed foronlymoderaterecoveryof osteogenesisimpairmentinduced byalcohol. Thereare several possible explanations for this observation.Itmaybethat theactivation ofWnt/ -catenin signaling or inhibition of TNF- $\alpha$ signaling was incomplete or suboptimal. Alternatively, it may be that multiple signaling pathways including Wnt/ $\beta$-catenin signaling and TNF- $\alpha$ signaling (and likely others as well) are involved in the regulation of differentiation of BMSCs after ethanol insult and intervention with any one of these pathways could elicit only a fractional changes of cell fate as the remaining pathways may well compensate for it. Or it is more likely that these above-mentioned two possibilities co-exist. To strengthen the efficacy of recovery of ethanol-induced osteogenesis impairment, one might simply elevate the concentrations of Wnt/ $\beta$-catenin activator or TNF- $\alpha$ inhibitor; however, this could well be in the face of generating non-specific and unwanted effects. An alternative approach is to simultaneously interfere Wnt/ $\beta$-catenin signaling and TNF- $\alpha$ signaling to achieve improved effects. The results in the present study indeed provided evidence in support of this latter strategy: concomitant activation of Wnt/ $\beta$-catenin signaling and inhibition of TNF- $\alpha$ signaling give rise to superior effects in terms of inhibition of ethanol-induced adipogenesis over interference of any one these pathways alone. This is expected if Wnt/ $\beta$-catenin signaling and TNF- $\alpha$ signaling are two separate signaling pathways. However, all these notions need to be examined by future studies.

Collectively, our study supports the finding that downregulation Wnt/ $\beta$-catenin signaling as an important determinant of ethanol-induced adipogenic shift of BMSCs [28]. Activation of Wnt/ $\beta$-catenin signaling partially reverted the impairment of osteogenesis. Moreover, simultaneous reciprocal interferences of Wnt/ $\beta$-catenin signaling and TNF$\alpha$ signaling yielded a significant improvement of effects on the recovery of osteogenesis. This strategy may therefore be considered as an alternative approach for the treatment of ethanol-induced impairment of osteogenesis. 
Chen et al.: Targeting TNF- $\alpha$ and Wnt1 to Induce Osteoblast Lineage of BMSCs

\section{Sources of Funding}

This study was supported partially by Guangxi Natural Science Foundation of China (Grant \# 2010GXNSFA013223), and by the key topics of the Guangxi Health Department (Grant \# 2010096).

\section{Conflicts of Interest}

The authors declare no conflicts of interest for this study.

\section{References}

1 Fancy SP, Harrington EP, Yuen TJ, Silbereis JC, Zhao C, Baranzini SE, Bruce CC, Otero JJ, Huang EJ, Nusse R, Franklin RJ, Rowitch DH: Axin2 as regulatory and therapeutic target in newborn brain injury and remyelination. Nat Neurosci 2011;14:1009-1016.

-2 Ao A, Hao J, Hopkins CR, Hong CC: DMH1, a novel BMP small molecule inhibitor, increases cardiomyocyte progenitors and promotes cardiac differentiation in mouse embryonic stem cells. PLoS One 2012; 7:e41627.

-3 Russo I, Caracciolo L, Tweedie D, Choi SH, Greig NH, Barlati S, Bosetti F: 3,6'-Dithiothalidomide, a new TNF- $\alpha$ synthesis inhibitor, attenuates the effect of A $\beta 1-42$ intracerebroventricular injection on hippocampal neurogenesis and memory deficit. J Neurochem 2012;122:1181-1192.

4 D'Amato RJ, Loughnan MS, Flynn E, Folkman J: Thalidomide is an inhibitor of angiogenesis. Proc Natl Acad Sci USA 1994;91:4082-4085.

-5 Włodarski KH: Haematopoietic and osteogenic bone marrow stem cells. Ortop Traumatol Rehabil 2011;13:439-447.

6 Pignolo RJ, Shore EM: Circulating osteogenic precursor cells. Crit Rev Eukaryot Gene Expr 2010;20:171180.

7 Wu JY, Scadden DT, Kronenberg HM: Role of the osteoblast lineage in the bone marrow hematopoietic niches. J Bone Miner Res 2009;24:759-764.

8 Heino TJ, Hentunen TA: Differentiation of osteoblasts and osteocytes from mesenchymal stem cells. Curr Stem Cell Res Ther 2008;3:131-145.

9 Derubeis AR, Cancedda R: Bone marrow stromal cells (BMSCs) in bone engineering: limitations and recent advances. Ann Biomed Eng 2004;32:160-165.

10 Mareddy S, Broadbent J, Crawford R, Xiao Y: Proteomic profiling of distinct clonal populations of bone marrow mesenchymal stem cells. J Cell Biochem 2009;106:776-786.

11 Potier E, Noailly J, Ito K: Directing bone marrow-derived stromal cell function with mechanics. J Biomech 2010;43:807-817.

12 Yang X, Matsuda K, Bialek P, Jacquot S, Masuoka HC, Schinke T, Li L, Brancorsini S, Sassone-Corsi P, Townes TM, Hanauer A, Karsenty G: ATF4 is a substrate of RSK2 and essential regulator of osteoblast biology: Implication for Coffin-Lowry Syndrome. Cell 2004;117:387-398.

13 Wek RC, Jiang HY, Anthony TG: Coping with stress: eIF2 kinases and translational control. Biochem Soc Trans 2006;34:7-11.

14 Vattem KM, Wek RC: Reinitation involving upstream ORFs regulates ATF4 mRNA translation in mammalian cells. Proc Natl Acad Sci USA 2004;101:11269-11274.

15 Gimble JM, Nuttall ME: The relationship between adipose tissue and bone metabolism. Clin Biochem 2012;45:874-879.

16 Peng S, Zhang G, He Y, Wang X, Leung P, Leung K, Qin L: Epimedium-derived flavonoids promote osteoblastogenesis and suppress adipogenesis in bone marrow stromal cells while exerting an anabolic effect on osteoporotic bone. Bone 2009;45:534-544.

-17 Liu TM, Martina M, Hutmacher DW, Hui JH, Lee EH, Lim B: Identification of common pathways mediating differentiation of bone marrow- and adipose tissue-derived human mesenchymal stem cells into three mesenchymal lineages. Stem Cells 2007;25:750-760.

18 Huang Q, Zhang H, Pei FX, Chen ZY, Wang GL, Shen B, Yang J, Zhou ZK, Kong QQ: Use of small interfering ribonucleic acids to inhibit the adipogenic effect of alcohol on human bone marrow-derived mesenchymal cells. Int Orthop 2010;34:1059-1068. 
Chen et al.: Targeting TNF- $\alpha$ and Wnt1 to Induce Osteoblast Lineage of BMSCs

19 Hamamura K, Yokota H: Stress to endoplasmic reticulum of mouse osteoblasts induces apoptosis and transcriptional activation for bone remodeling. FEBS Lett 2007;581:1769-1774.

20 Nusse R, Varmus HE: Wnt genes. Cell 1992;69:1073-1087.

-21 Laine CM, Joeng KS, Campeau PM, Kiviranta R, Tarkkonen K, Grover M, Lu JT, Pekkinen M, Wessman M, Heino TJ, Nieminen-Pihala V, Aronen M, Laine T, Kröger H, Cole WG, Lehesjoki AE, Nevarez L, Krakow D, Curry CJ, Cohn DH, Gibbs RA, Lee BH, Mäkitie O: WNT1 mutations in early-onset osteoporosis and osteogenesis imperfecta. N Engl J Med 2013;368:1809-1816.

-22 Liu G, Vijayakumar S, Grumolato L, Arroyave R, Qiao H, Akiri G, Aaronson SA: Canonical Wnts function as potent regulators of osteogenesis by human mesenchymal stem cells. J Cell Biol 2009;185:67-75.

23 Robinson JA, Chatterjee-Kishore M, Yaworsky PJ, Cullen DM, Zhao W, Li C, Kharode Y, Sauter L, Babij P, Brown EL, Hill AA, Akhter MP, Johnson ML, Recker RR, Komm BS, Bex FJ: Wnt/beta-catenin signaling is a normal physiological response to mechanical loading in bone. J Biol Chem 2006;281:31720-31728.

24 Day TF, Guo X, Garrett-Beal L, Yang Y: Wnt/beta-catenin signaling in mesenchymal progenitors controls osteoblast and chondrocyte differentiation during vertebrate skeletogenesis. Dev Cell 2005;8:739-750.

-25 Hill TP, Spater D, Taketo MM, Birchmeier W, Hartmann C: Canonical Wnt/beta-catenin signaling prevents osteoblasts from differentiating into chondrocytes. Dev Cell 2005;8:727-738.

26 Bennett CN, Ouyang H, Ma YL, Zeng Q, Gerin I, Sousa KM, Lane TF, Krishnan V, Hankenson KD, MacDougald OA: Wnt10b increases postnatal bone formation by enhancing osteoblast differentiation. J Bone Miner Res 2007;22:1924-1932.

27 Morvan F, Boulukos K, Clément-Lacroix P, Roman Roman S, Suc-Royer I, Vayssière B, Ammann P, Martin P, Pinho S, Pognonec P, Mollat P, Niehrs C, Baron R, Rawadi G: Deletion of a single allele of the Dkk1 gene leads to an increase in bone formation and bone mass. J Bone Miner Res 2006;21:934-945.

28 Chen JR, Lazarenko OP, Shankar K, Blackburn ML, Badger TM, Ronis MJ: A role for ethanol-induced oxidative stress in controlling lineage commitment of mesenchymal stromal cellsthrough inhibition of Wnt/beta-catenin signaling. J Bone Miner Res 2010;25:1117-1127.

-29 Wahl EC, Aronson J, Liu L, Liu Z, Perrien DS, Skinner RA, Badger TM, Ronis MJ, Lumpkin CK Jr: Chronic ethanol exposure inhibits distraction osteogenesis in a mouse model: role of the TNF signaling axis. Toxicol Appl Pharmacol 2007;220:302-310.

30 Wang Y, Li Y, Mao K, Li J, Cui Q, Wang GJ: Alcohol-induced adipogenesis in bone and marrow: a possible mechanism for osteonecrosis. Clin Orthop Relat Res 2003;410:213-224.

-31 Cui Q, Wang Y, Saleh KJ, Wang GJ, Balian G: Alcohol-induced adipogenesis in a cloned bone-marrow stem cell. J Bone Joint Surg Am 2006;88 Suppl 3:148-154.

-32 Rosa ML, Beloti MM, Prando N, Queiroz RH, de Oliveira PT, Rosa AL: Chronic ethanol intake inhibits in vitro osteogenesis induced by osteoblasts differentiated from stem cells. J Appl Toxicol 2008;28:205-211.

-33 Diamond T, Stiel D, Lunzer M, Wilkinson M, Posen S: Ethanol reduces bone formation and may cause osteoporosis. Am J Med 1989;86:282-288.

34 Pittenger MF, Mackay AM, Beck SC, Jaiswal RK, Douglas R, Mosca JD, Moorman MA, Simonetti DW, Craig S, Marshak DR: Multilineage potential of adult human mesenchymal stem cells. Science 1999;284:143-147.

35 Klein RF: Alcohol-induced bone disease: impact of ethanol on osteoblast proliferation. Alcohol Clin Exp Res 1997;21:392-399.

-36 Sato N, Meijer L, Skaltsounis L, Greengard P, Brivanlou AH: Maintenance of pluripotency in human and mouse embryonic stem cells through activation of Wnt signaling by a pharmacological GSK-3-specific inhibitor. Nat Med 2004;10:55-63.

-37 Fragoso MA, Patel AK, Nakamura RE, Yi H, Surapaneni K, Hackam AS. The Wnt/ $\beta$-catenin pathway cross-talks with STAT3 signaling to regulate survival of retinal pigment epithelium cells. PLoS One 2012; 7:e46892.

-38 Ducy P, Zhang R, Geoffroy V, Ridall AL, Karsenty G: Osf2/Cbfa1: a transcriptional activator of osteoblast differentiation. Cell 1997;89:747-754.

39 McKee MD, Nanci A: Osteopontin: an interfacial extracellular matrix protein in mineralized tissues. Connect Tissue Res 1996;35:197-205.

40 Aubin JE, Liu F: The osteoblast lineage; in Bilezikian JP, Raisz LG, Rodan GA (eds): Principles of Bone Biology. San Diego, Academic Press; 1996, pp 51-67.

-41 Verras M, Papandreou I, Lim AL, Denko NC: Tumor hypoxia blocks Wnt processing and secretion through the induction of endoplasmic reticulum stress. Mol Cell Biol 2008;28:7212-7224.

42 Wei L, Sun C, Lei M, Li G, Yi L, Luo F, Li Y, Ding L, Liu Z, Li S, Xu P: Activation of Wnt/ $\beta$-catenin pathway by exogenous Wnt1 protects SH-SY5Y cells against 6-hydroxydopamine toxicity. J Mol Neurosci 2013;49:105115. 